\title{
Culvert Analysis Program Graphical User Interface 1.0- A Preprocessing and Postprocessing Tool for Estimating Flow Through Culverts
}

\section{Introduction}

The peak discharge of a flood can be estimated from the elevation of high-water marks near the inlet and outlet of a culvert after the flood has occurred. This type of discharge estimate is called an "indirect measurement" because it relies on evidence left behind by the flood, such as high-water marks on trees or buildings. When combined with the cross-sectional geometry of the channel upstream from the culvert and the culvert size, shape, roughness, and orientation, the high-water marks define a water-surface profile that can be used to estimate the peak discharge by using the methods described by Bodhaine (1968). This type of measurement is in contrast to a "direct" measurement of discharge made during the flood where cross-sectional area is measured and a current meter or acoustic equipment is used to measure the water velocity. When a direct discharge measurement cannot be made at a streamgage during high flows because of logistics or safety reasons, an indirect measurement of a peak discharge is useful for defining the high-flow section of the stage-discharge relation (rating curve) at the streamgage, resulting in more accurate computation of high flows.

The Culvert Analysis Program (CAP) (Fulford, 1998) is a command-line program written in Fortran for computing peak discharges and culvert rating surfaces or curves. CAP reads input data from a formatted text file and prints results to another formatted text file. Preparing and correctly formatting the input file may be time-consuming and prone to errors. This document describes the CAP graphical user interface (GUI) - a modern, cross-platform, menu-driven application that prepares the CAP input file, executes the program, and helps the user interpret the output.

\section{Description of the CAP GUI}

The CAP GUI is organized around a series of input screens that specify the culvert type, the approach section geometry, the spatial relation between the two, and the depth of the flow. A representative sample of the input screens is shown in figure 1. The input screens are accessed from a series of menus that are arranged from left to right in the order that the data typically are entered.

The New Indirect item from the File menu opens an input screen for basic information about the flood, the survey, the system of units, and the personnel involved. This information can be edited later by selecting Project Info (fig. $1 \mathrm{~A}$ ) from the General menu. This information is not used in the computation of peak discharges or in the culvert rating.

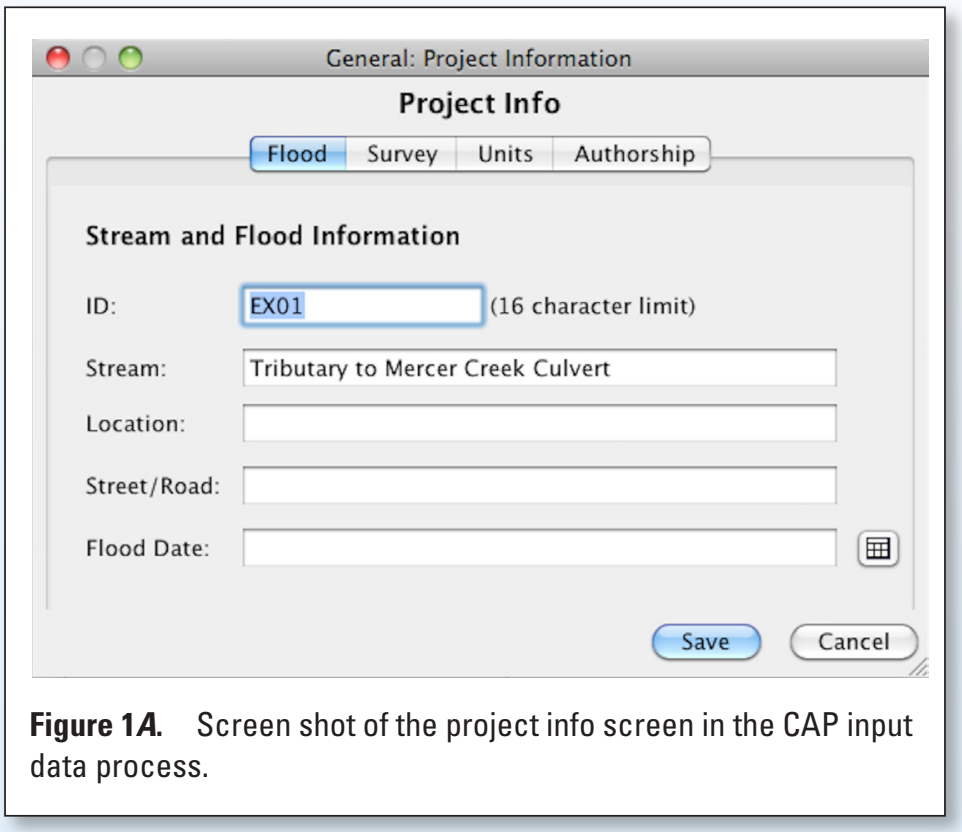

The Shape menu defines the culvert shape. Five shapes are supported: box, circular (fig. $1 B$ ), elliptical, pipe arch, and non-standard.

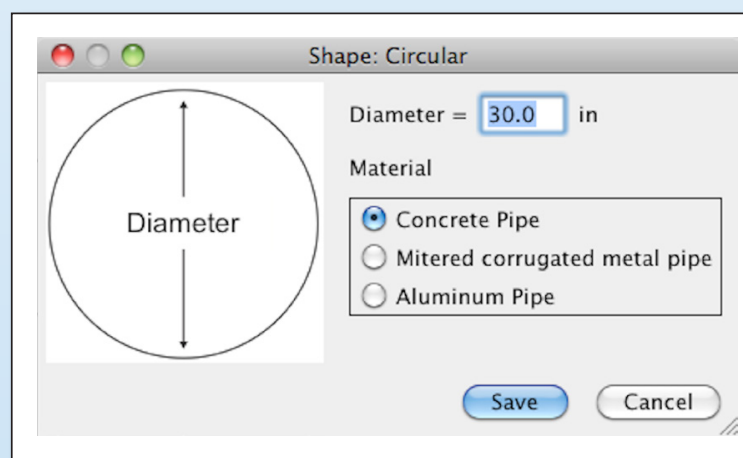

Figure 1B. Screen shot of the shape input example in the CAP input data process. 
The Alignment menu specifies how the culvert is aligned in relation to the road and the flow. Three alignment options are supported: unskewed (fig. $1 C$ ), skewed road to flow, and mitered culvert.

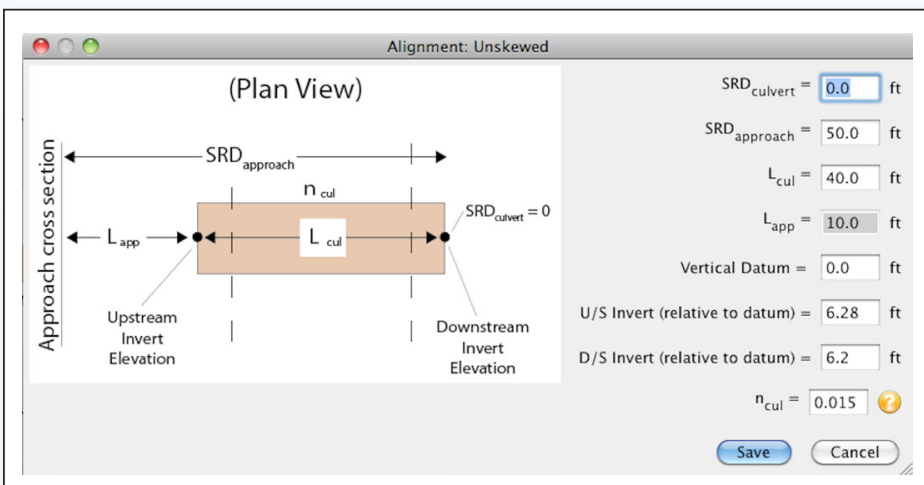

Figure 1C. Screen shot of the alignment input example in the CAP input data process (SRD, section reference distance).

The culvert edging is defined using the Edging menu. Available options are no edging, rounding, beveled (fig. 1D), bell mouth or tongue and groove, mitered end, and flared pipe.

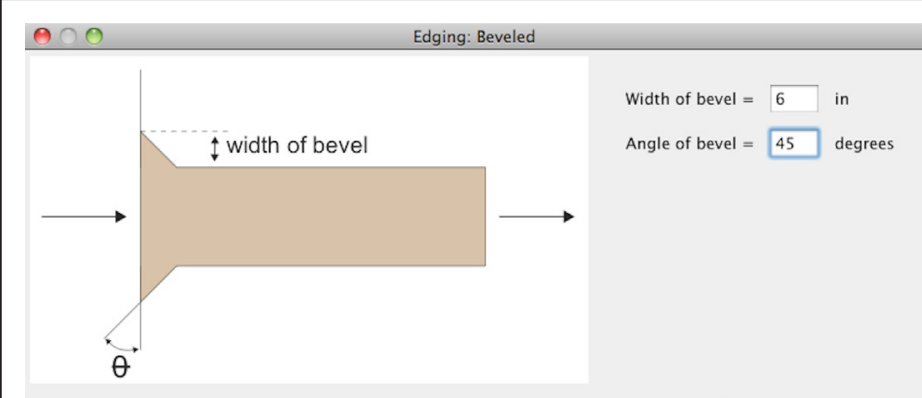

Save Cancel

Figure 1D. Screen shot of the edging input example in the CAP input data process.

The Wingwalls menu allows culvert wingwalls to be specified as none, equal angled (fig. $1 E$ ), or unequal angled.

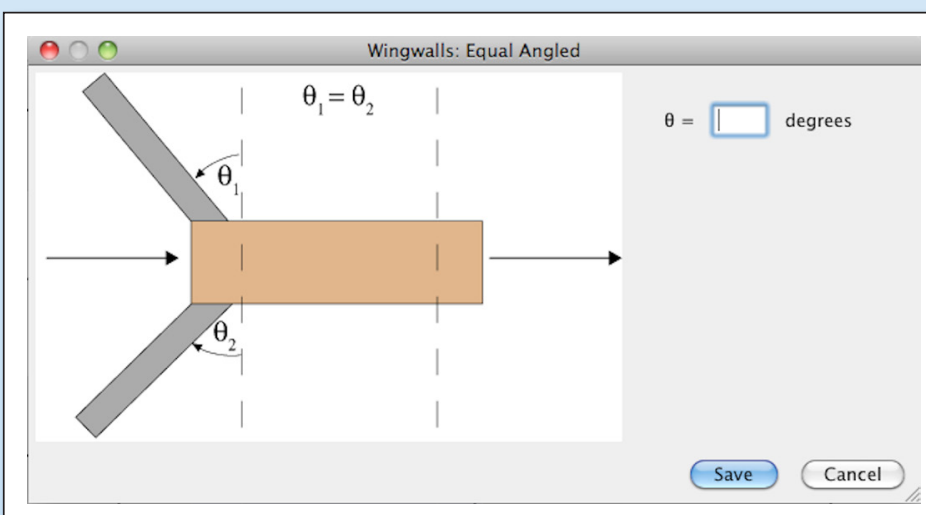

Figure 1E. Screen shot of the wingwalls input example in the CAP input data process.
Culvert projection, either flush, equal projection (fig. $1 F$ ), or unequal projection, is defined using the Projection menu.

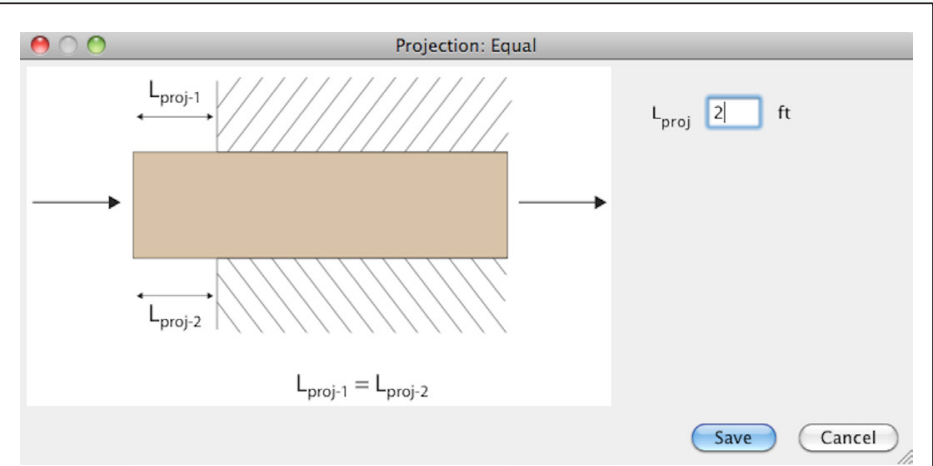

Figure 1F. Screen shot of the culvert projection input example in the CAP input data process.

The Approach menu is used to define the approach cross-section location, geometry (fig. $1 G$ ), roughness, and water-surface elevation.

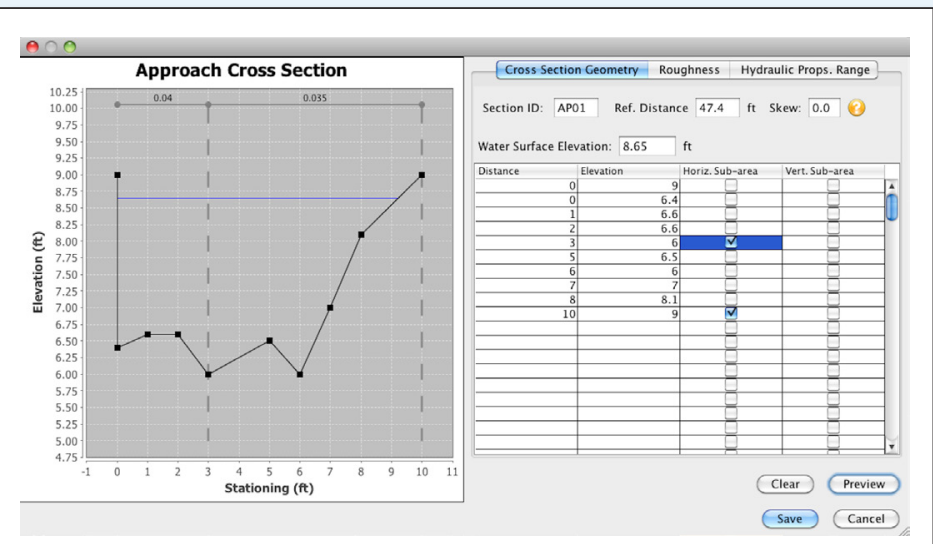

Figure 1G. Screen shot of the approach cross section input screen in the CAP input data process.

The flows (fig. $1 H$ ) and tailwater elevations (fig. $1 I$ ) that CAP should evaluate are defined using the Flow/Tailwater menu. Up to 48 discharges and 50 tailwater elevations are supported.

Figure $1 H$. Screen $\theta \cap 0 \quad$ Flow

shot of the flow Enter up to 48 discharges (cfs):

input screen in the

CAP input data

process.

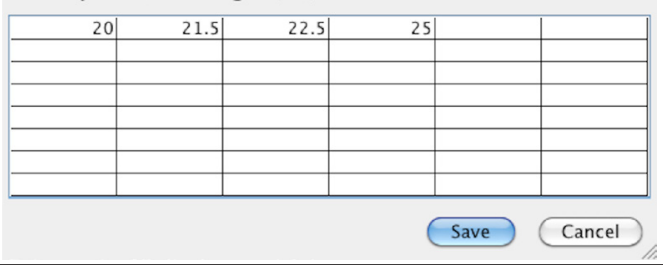

Figure 11. Screen shot of the tailwater input screen in the CAP input data process.

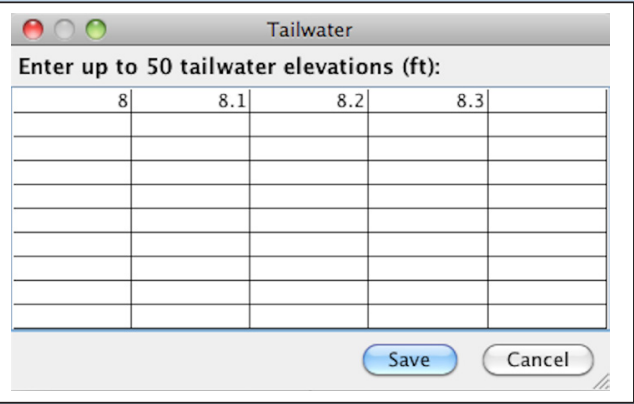


Optional coefficients are entered using the Coefficients menu. The coefficients for flow types 1, 2, and 3 (fig. $1 J$ ) can be specified as an entrance coefficient rating curve or as discharge coefficient adjustments based on the details of the shape of the culvert entrance. The coefficients for flow types 4 , 5 , and 6 are defined as an entrance coefficient rating curve. The type of high-head flow and the elevation at which the transition between flow types 5 and 6 occurs may also be defined.

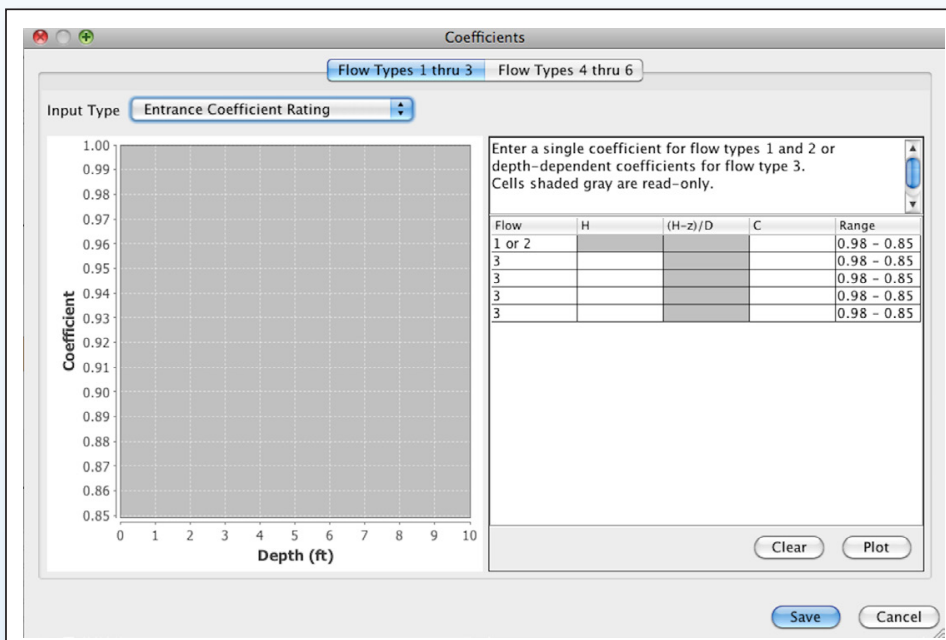

Figure 1J. Screen shot of the discharge coefficients input screen in the CAP input data process.

Once all the data are entered, the CAP menu controls execution of the CAP program and access to the output. The Run CAP item opens a dialog box where the user specifies the locations of the CAP input and output files. Before the CAP GUI executes CAP, it performs basic validation steps to ensure that all required data have been supplied and that all data are the correct type. It does not verify that the data are sensible.

If CAP executes successfully, the GUI presents the output in a variety of ways, all accessible through the CAP menu. Plots include the energy profile (fig. $2 A$ ), approach section water surface elevation versus discharge for a given tailwater elevation (fig. $2 B$ ), and discharge versus tailwater elevation for a given approach water-surface elevation (not shown). Right-clicking on a plot displays a menu with a variety of options to customize the plot or export a high-resolution version to a file. The CAP GUI does not directly create plots for the tailwater elevation contours and the culvert rating surface. Instead, an option to export a script (fig. $2 C$ ) that will create those plots using the free R statistical package (http://www.r-project.org/) is available (fig. $2 D, 2 E$ ). The GUI also presents a table of approach elevations as a function of discharge and tailwater elevation (fig. $2 F$ ). This data table is the equivalent of the 3-parameter table computed by CAP and can be electronically copied and pasted into a text file or spreadsheet for further analysis using standard keyboard shortcuts. The raw CAP output file also is available.

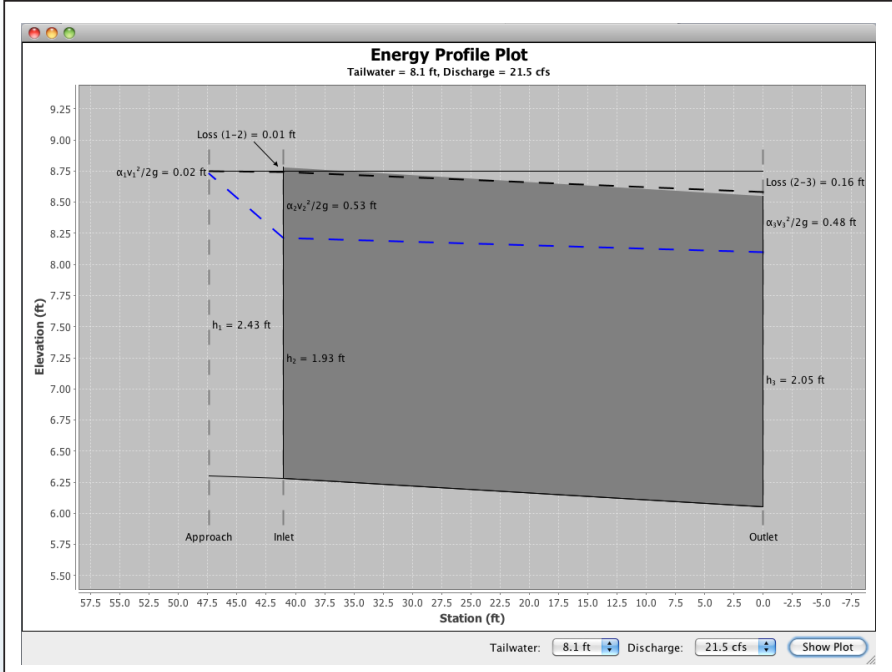

Figure 2A. Screen shot of an energy profile output plot from the CAP GUI.

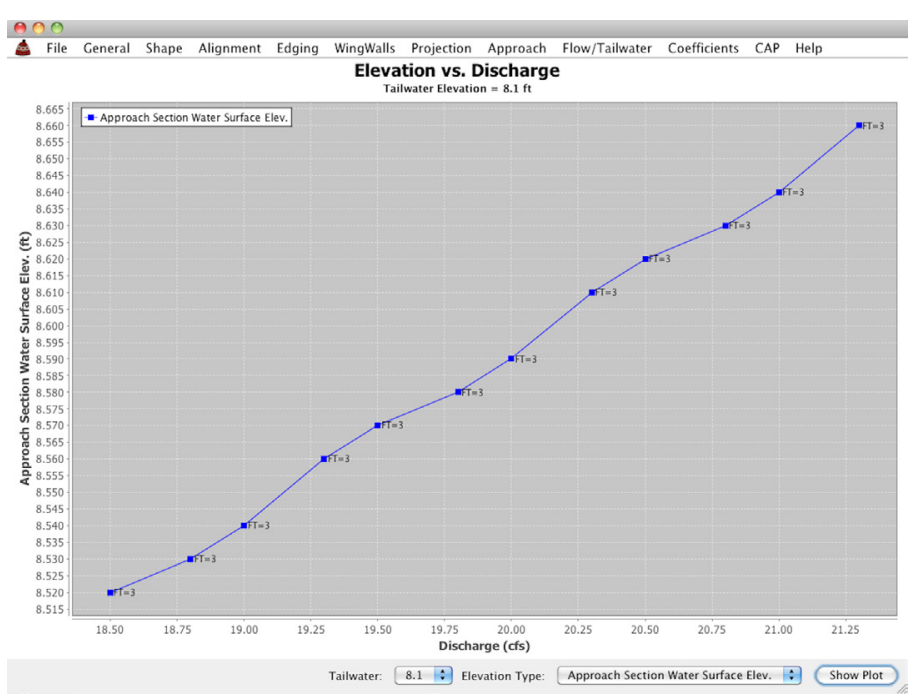

Figure 2B. Screen shot of an approach section water surface elevation versus discharge output plot from the CAP GUI.

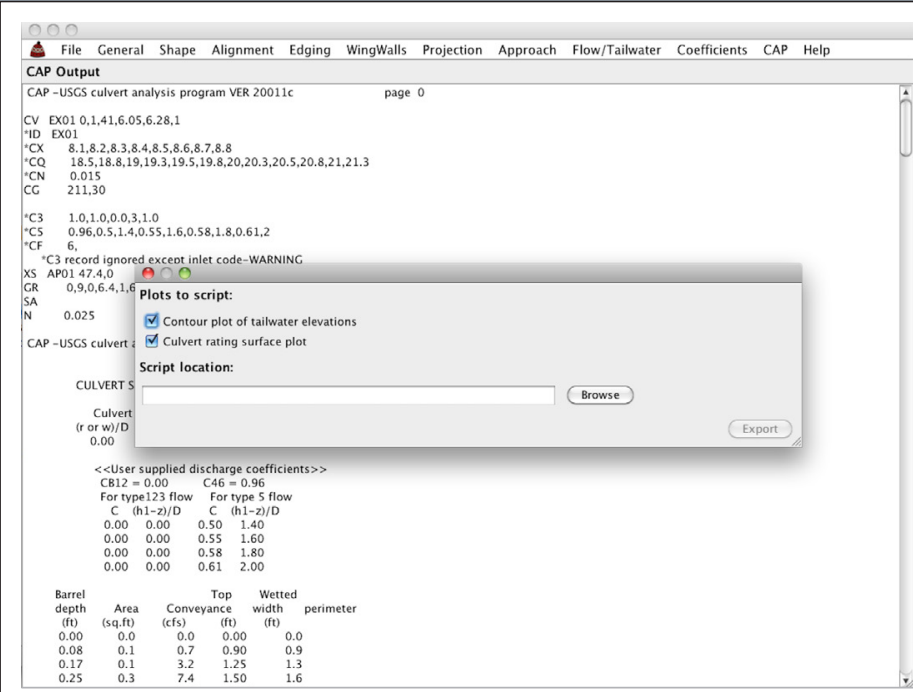

Figure 2C. Screen shot of the R-script export dialog from the CAP GUI with CAP output file in the background. 

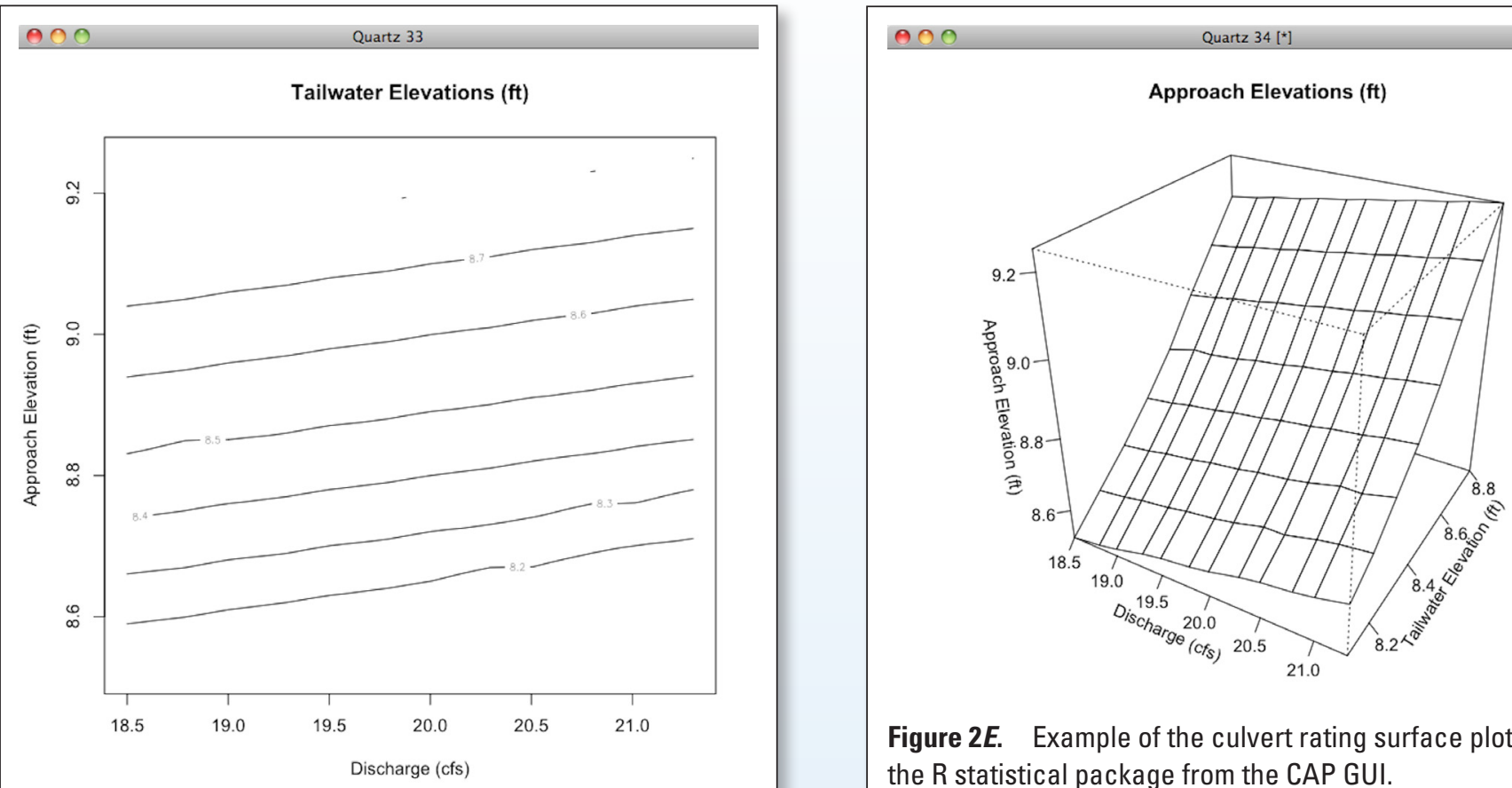

Figure 2E. Example of the culvert rating surface plotted by the $\mathrm{R}$ statistical package from the CAP GUI.

Figure 2D. Example of the tailwater elevations contour plot generated by the R statistical package from the CAP GUI.

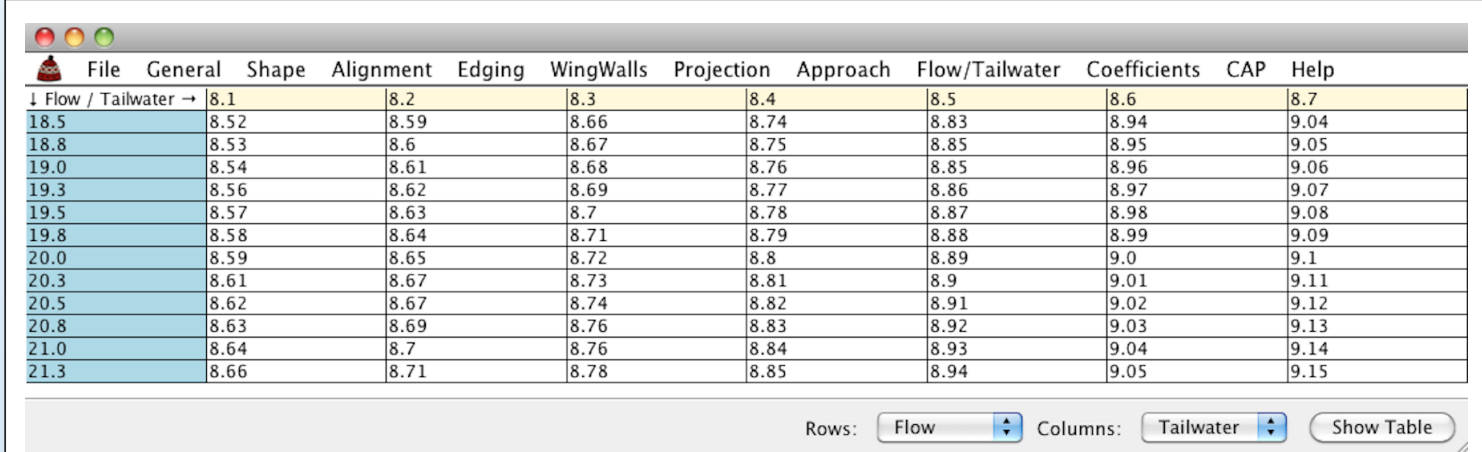

Figure 2F. Screen shot of the 3-parameter table from the CAP GUI, listing the computed approach section elevation for all combinations of flow and tailwater elevation.

\section{Obtaining and Installing CAP and the CAP GUI}

The CAP GUI is a Java program that interfaces with the CAP command-line Fortran program. The CAP GUI and CAP have been run successfully under Windows and Macintosh operating systems. CAP GUI, CAP, example datasets, documentation, installation requirements, and an installer are available from the CAP/CAP GUI Web page (http://water.usgs. gov/software/CAP/).

For more information about the CAP GUI, please contact h2osoft@usgs.gov

\section{References}

Bodhaine, G.L., 1968, Measurement of peak discharge at culverts by indirect methods: U.S. Geological Survey Techniques of Water-Resources Investigations, book 3, chap. A3, $60 \mathrm{p}$.

Fulford, J.M., 1998, User's guide to the U.S. Geological Survey Culvert Analysis Program, Version 97-08: U.S. Geological Survey Water-Resources Investigations Report 98-4166, $70 \mathrm{p}$. 